the exact decomposition pressure of any particular chloride. This was not done in the study carried out by Hildebrand (loc cit.). This point is receiving attention at present in this laboratory, more especially in the determination and separation of anions by use of a silver or some other suitable anode.

A very interesting feature of the particular studies here described as well as a portion of those communicated by McCutcheon (p. I 449) is that by the current, applied as it has been in this laboratory, many interesting separations are now possible in the groups of the alkali and alkaline earth metals. Even inexperienced persons can carry out such separations. Further, many of these surpass the ordinary gravimetric procedures both in accuracy and in the short time necessary for their execution.

The analyst is not restricted any longer, in the application of the current in analysis, to the determination of such metals as copper, nickel, zinc, lead, etc. The field is now vastly broader. Anions may be most accurately determined and probably be separated in many instances more successfully than in any other way. While not desiring to anticipate another investigation now in progress, it may be mentioned that in plating anodes like those used in the present study and by McCutcheon, and by Hildebrand in their particular researches, with a suitable, adherent coating, such as calcium hydroxide, soluble fluorides may be electrolytically analyzed in the cell used in this laboratory, with the outcome that both the anion, fluorine, and the cation, sodium, can be most accurately determined. What further progress in this field may bring, one can scarcely say, yet in the language of the immortal Faraday we may rest assured "that advancement in it, whether in degree great or small, instead of exhausting the subject of research, will open doors to future and more abundant knowledge, overflowing with beauty and utility to those who will be at the $*^{*} * * *$ pains of undertaking its experimental investigation."

UNIVERSITY OF PENNSYlVANIA.

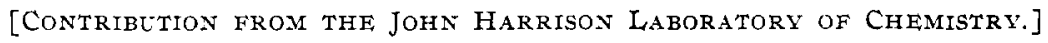

\title{
THE ELECTROLYSIS OF METALLIC CHLORIDE SOLUTIONS WITH THE USE OF ROTATING SILVER ANODE AND MERCURY CATHODE.
}

BY Thomas P. MCCUTChEON JR. AND EDgaR F. SMITH.

Received August I5, 1907 .

In previous communications it has been shown how readily certain bodies, e. g., barium chloride, may be electrolyzed in the cell of Hildebrand. ${ }^{1}$ It occurred to us that a study of metallic halides, in general, might reveal something of interest. To this end solutions of chlorides, as neutral as they could be obtained, were made up so that in a dilution of 50 cubic

1 This Journal, 29, 447. 
centimeters there was present approximately o. I gram of metal. The anode made about 200 revolutions per minute. The pressure equaled, unless otherwise stated, 8 volts.

On introducing a solution of cerous chloride into the inner compartment and arranging the cell as usually done it was noticed that at the beginning, on applying a current of 0.8 to 0.02 ampere and from 8 to Io volts, a cerium amalgam was formed. This was evident from the appearance of the surface of the mercury cathode. After the chlorine had gone to the anode of silver and the current had fallen to about 0.5 ampere, the amalgam began to decompose and the solution in the inner compartment became red in color by transmitted light (like potassium permanganate), while by reflected light a greenish fluorescence, as seen in crude petroleum, was distinctly visible. This solution lost none of its properties on filtering. On the addition of common salt it gave a reddish brown precipitate, indicating that the liquid contained some colloidal cerium compound.

The fact that in the course of the electrolysis the current fell to 0.2 o.or ampere would indicate that the cerium compound, in the solution, was not ionized. On allowing the electrolysis to continue for some time after the ammeter had fallen to 0.02 ampere, the colloid separated completely in the form of a reddish brown precipitate which floated about in the agitated water.

Reactions of the Colloidal Cerium Solution.

Ammonia..........................

Sodium Chloride.................. " " "

Potassium Hydroxide ................ dilute solution was added slowly,--the cerium solution became almost colorless, a slight brownish tint, no precipitate. After adding potassium permanganate and treating with ammonia, a precipitate formed resembling cerous hydroxide.

Potassium Chromate..$\ldots \ldots \ldots \ldots \ldots \ldots \ldots$ brownish red precipitate.

Potassium Iodide $\ldots \ldots \ldots \ldots \ldots \ldots \ldots \ldots \ldots$

Stannous Chloride $\ldots \ldots \ldots \ldots \ldots \ldots \ldots \ldots \ldots$

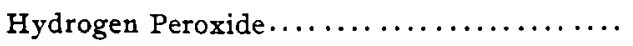

and ammonia, yellow precipitate resembling the hydrated dioxide of cerium.

When dilute sulphuric acid and potassium iodide were added to the colloidal solution and the liquid warmed, the brownish red precipitate separated at first, after which iodine was liberated and was collected in carbon bisulphide. This reaction is characteristic of cerium dioxide.

On warming the colloidal solution with dilute sulphuric acid and al- 
cohol, the odor of aldehyde was evident. These two reactions reduce cerium dioxide to the sesquioxicie.

In concentrated sulphuric acid the colloidal solution became yellow in color. Upon adding ferrous sulphate and then ammonium hydroxide, a precipitate of ferric hydroxide separated, showing that the colloidal solution possessed oxidizing action.

The reddish brown precipitate a mixtare of oxides.--While cerous hydroxide is not readily or completely soluble in hydrochloric acid, and yellow hydrated dioxide of ceritum, (made by passing chlorine into cerous hydroxicle, suspended in caustic soda), dissolves easily in hydrochloric acid, the red hydrated trioxide of cerium (made by the action of ammonia and hydrogen peroxide on a cerous salt), is also readily soluble in hydrochloric acid.

When the colloidal solution is treated with hydrogen peroxide or hydrogen peroxide and ammonia, it gives a yellowish red precipitate, different however from the hydrated trioxide. It turns yellowish white in color when treated with concentrated hydrochloric acid.

A portion of the colloidal solution was precipitated with sodium chloride. The precipitate was washed, boiled with concentrated hydrochloric acid and filtered. There was a yellowish white residue. It turned yellow when heated with hydrogen peroxide, or with ammonia and hydrogen peroxide, while hydrochloric acid changed it back to the yellowish white body. Evidently then the precipitate was not the hydrated trioxide.

The filtrate from the yellowish white residue mentioned in the last paragraph gave a red hydrated trioxide with ammonia and hydrogen peroxide. So then part of the reddish brown precipitate is soluble in hydrochloric acid and part is insoluble. It is evidently a mixture of oxides.

The higher oxides of cerium dissolve readily in hydrochloric acid, the lowest does not (except when freshly precipitated.) When the colloidal solution was allowed to stand for several weeks, the brownish red precipitate separated of its own accord. When the colloidal solution was placed in a dialyzer; the usual precipitate separated in about two hours. This also happened with the colloidal neodymium solution mentioned later. Mere boiling of the colloidal cerium solution caused the reddish brown precipitate to separate.

When cerous chloride solutions were electrolyzed with a stationary anode, a white preciptate of cerous hydroxide appeared. No colloid was formed. 'The current fell to 0.03 ampere.

A pressure of eight volts is most favorable for the formation of the colloidai solution. No colloid was produced with 3 volts or with 5 volts, but at 8 volts, the solution began to take on a pink color, showing the 
formation of the colloid. Higher voltages than 8 caused a rapid separation of the reddish brown precipitate.

With lanthanum chloride a current of 8 volts and 0.3 to 0.01 ampere gave at first an amalgam. There was no separation of hydroxide in the inner compartment, but the clear and filtered liquid showed a yellow tint. This colloidal solution remained stable for several weeks. Ammonium hydroxide and common salt produced white precipitates when introduced in to it.

An amalgam also appeared on electrolyzing a solution of neodymium chloride. The liquid gradually became opalescent and in the course of a few days it acquired a deep purplish color. A solution of salt produced a white precipitate. The current employed in this experiment varied from 0.10 to 0.02 ampere.

Praseadymium chloride behaved like the neodymium salt. The colloilal solution showed slight opalescence with a brownish tint. It gave a white precipitate with common salt

In the case of yttrium chloride a rather stiff amalgam was formed at first, then a white hydroxide appeared, but on filtering it out the filtrate, slightly opalescent in appearance, gave a very distinct precipitale on the addition of a common salt solution. The yttrium colloidal solution is very stable.

When ferric chloride is electrolyzed in an ordinary mercury cup, using toluene to absorb or remove the chlorine a determination of the iron may be very accurately made. Ferric chloride, in the cell used with the preceding chlorides, exposed to the action of 8 volts and 0.8 to 0.04 ampere, became almost colorless and dark blotches appeared on the surface of the mercury cathode during which period the solution acquired a more intense browuish yellow color than at first. Quite a little precipitate separated. The filtrate from it, however, showed a brown color and when treated with sodium chloride gave a reddish brown precipitate, resembling ferric hydroxide. The colloidal solution suffered no change upov standing for several weeks. It gave no coloration on the addition 0 . potassium sulphocyanide. If, however, the precipitate, thrown out of the colloidal solution by salt, was dissolved in hydrochloric acid and sulphocyanide added to this solution, blood red colored ferric sulphocyanide appeared. The colloidal solution could not then have contained ferric ions.

Further, when the colloidal solution was digested with hydrochloric acid and potassium iodide, iodine was liberated.

The electrolysis of a solution of aluminium chloride gave a gelatinous precipitate almost immediately. The filtrate from it was slightly opalescent and continued stable for several weeks. Sodium chloride produced a precipitate, soluble in sodium hydroxide. 
The electrolysis of a solution of chromizm chloride gave a green precipitate. The solution from the latter showed no chromium. When the current of 0.9 ampere and 5 volts had fallen to 0.05 ampere a colloidal body seemed to form, because on filtering out the precipitate at this point there remained a solution green in color from which common salt precipitated chromium hydroxide. If the current was allowed to fall to 0.03 ampere, and the precipitate was then removed, its filtrate did not show the presence of chromium.

These represent our experiences in electrolyzing the chlorides of sesquioxides.

Turning for a moment to chlorides of protoxides it may be noted that if cobaltous chloride yields a colloidal hydroxide it is very unstable. Colloidal bodies were not obserred with manganese and glucinum. In the case of cadnium chloride, the hydroxide of the metal alone was produced. Stannous chloride gave, at first an amalgam, with the separation of some hydroxide, but on filtering this out, the filtrate while clear, was brown in color and gave a brown precipitate upon the addition of a salt solution. Ammonium hydroxide was without effect. The colloidal solution became darker in color on heating, separating eventually a dark precipitate. The solution showed no reducing action with potassium permanganate. Iodine did not separate when it was treated with hydrochloric acid and potassium iodide.

Colloidal solutions were not obtained with zinc, nickel or copper. The chloride of the latter gives at first white cuprous chloride.

Stannic chloride gave an abundance of stannic hydroxide almost imme. diately. There was no evidence of colloidal formation. There seemed to be a slight colloidal production with thorium chloride, but it soon separated from its solution, while with zirconium and titanium there was complete absence of anything like a colloidal state. Uranium chloride gave rise to an unstable colloidal hydroxide from which uranic hydroxide soon separated.

It may then be concluded that in electrolyzing metallic chlorides as outlined in the preceding paragraphs, stable colloidal hydroxide solutions will be found with those of the sesquioxide type, while with chlorides of the dioxide and protoxide types such formation will not arise, or if it does, it will be extremely unstable.

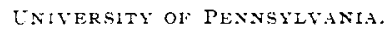

\section{NOTES ON VOLUMETRIC DETERMINATION OF MAGNESIUM IN WATER. \\ DY G. B. FRANKFORTER AN LIILIAN COHEN. Received August 23, 1907 .}

A rapid method for the determination of magnesium in water must necessarily be of great importance to the water analyst. The writers, 